\title{
84. On the Formation of Lysolecithin from Egg-yolk Lecithin by Pancreas Extract.
}

\author{
By Ziro Nikuni.
}

Agricultural Chemical Laboratory, Tokyo Imperial University, Komaba.

(Comm. by U. Suzuki, M.I.A., July 12, 1932.)

Since the discovery of lysolecithin by Delezenne and Fourneau (Bull. Soc. Chim. iv, 15, 421, 1914) many works have been done on this subject and it is now generally recognized that the formation of this substance from lecithin by the action of snake venom is due to an enzyme "Lecithinase" in it.

On the other hand, the existence of an enzyme which splits lecithin into fatty acids, glycerophosphoric acid and cholin, was found by Bókay (H. 1, 157, 1877) in cow pancreas. This enzyme seems to be widely distributed in blood, liver, brain and other organs, as well as in egg-yolk, castor bean and Takadiastase etc. So, the question naturally arises whether it is the same with the lecithinase of snake venom, or whether lysolecithin is also formed from lecithin during the digestion with this enzyme.

Contardi and Latzer (Bioch. Z. 197, 222, 1928) obtained a haemolytic substance from the digestion products of lecithin by Ricinus lipase. Wohlgemuth (Bioch. Z. 39, 302, 1912) found a haemolytic substance in human pancreatic juice, and Belfanti (Bioch. Z. 154, 148, 1924 ; Z. f. Imm. 44, 347, 1925; 56, 449, 1928) isolated lysolecithin from pancreas and salivary glands of horse and cow, and supposed that the latter might be formed by the enzyme contained in these organs, but no decisive proof has been given on this subject.

According to the sugestion of Prof. U. Suzuki, the present author tried to digest egg-yolk with pancreas extract or with commercial pancreatin, and observed that a powerful haemolytic substance was formed during the digestion, which disappeared again on further standing. After many trials, the author succeeded in isolating this substance in crystalline state and proved it to be identical with lysolecithin, formed by snake venom. It was further observed that a haemolytic substance is also formed by commercial Takadiastase in the same way.

\section{Experimental.}

(1) Digestion of egg-yolk lecithin with pancreas extract. 
The pancreas extract containing lecithinase was prepared according to the method of Willstaetter (H. 125, 153, 1923) using fresh pig pancreas.

Sometimes, the finely minced pancreas paste was directly used for the same purpose.

Fresh egg-yolk was mixed with N/15 potassium-phosphate solution and digested with pancreas extract at $36-38^{\circ}$, being added with a little toluol. The mixture was frequently shaken, and from time to time a definite amount was taken out from it and added with $95 \%$ alcohol. The precipitate formed thereby was filtered off, and the filtrate was evaporated nearly to dryness, and treated with a small amount of absolute alcohol, filtered, and to the filtrate an alcoholic solution of cadmium chloride was added, whereby the lysolecithin together with lecithin were precipitated as the double salts. These were collected, dried, and again dissolved in $0.9 \% \mathrm{NaCl}$ solution and tested for haemolytic power according to the Hirao's method (J. Agr. Chem. Soc. Japan, 6, 738, 1930), using $2 \%$ suspension of red blood corpuscles. The experiment was repeated several times with nearly the same result. For example, one experiment is given below.

Experiment: as the source of lecithinase, either $5 \mathrm{~g}$. of pancreas paste, or $12 \mathrm{~g}$. of glycerin extract obtained from $5 \mathrm{~g}$. pancreas paste, were used. Five fresh egg-yolks were well mixed with N/15 potassiumphosphate solution, and filled up to $300 \mathrm{cc}$. Each $100 \mathrm{cc}$. of this mixture was now treated as follows.

1. Control: $\quad 100 \mathrm{cc}$. yolk solution and $3 \mathrm{cc}$. toluol.

2. Pancreas paste: $100 \mathrm{cc}$. yolk solution and $3 \mathrm{cc}$. toluol and $5 \mathrm{~g}$. paste.

3. Glycerin extract: $100 \mathrm{cc}$. yolk solution and $3 \mathrm{cc}$. toluol and $12 \mathrm{~g}$. extract.

The digestion was carried out at $36-38^{\circ}$. Each $5 \mathrm{cc}$. was taken out from time to time, and tested for haemolytic power as descrived above. Control showed almost no haemolytic power throughout the experimental period.

The results are shown graphically as follows (Fig. I).

In Fig. I, the number 40,000 for instance,

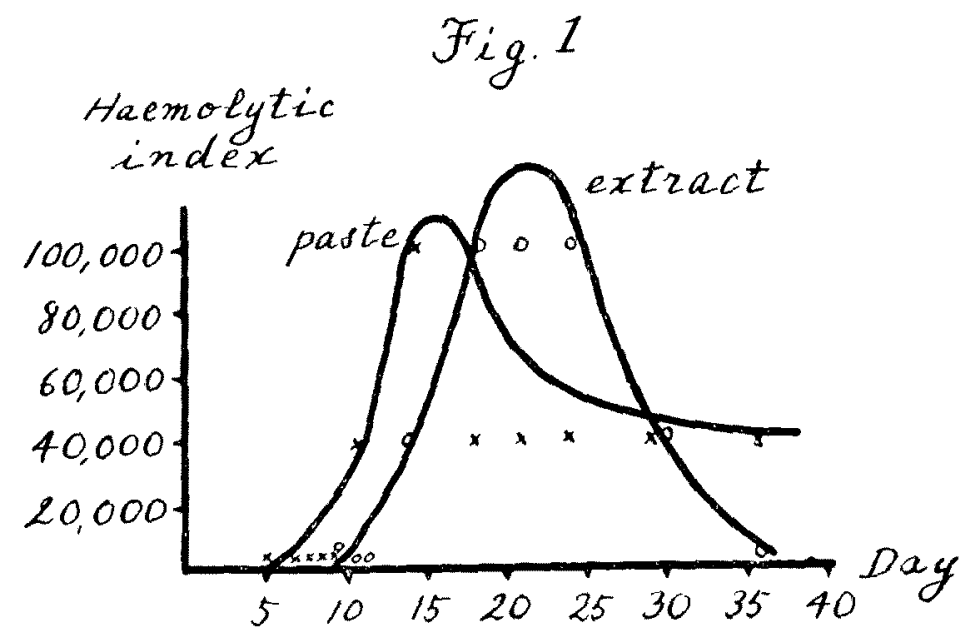


indicates the Haemolytic Index (Kofler: Die Saponine, 148, 1927) showing that the $1 / 40,000$ solution of the sample to be tested, causes the complete haemolysis.

The above results show that, during the digestion of egg-yolk with pancreas extract, a substance of strong haemolytic power is formed. The highest activity being attained after 10-20 days. After that time, it decreases rapidly and finally disappears.

(2) Digestion of egg-yolk lecithin with commercial pancreatin.

The above experiment was repeated with commercial pancreatin, prepared by Konishi \& Co. officinally from pig pancreas (The Japanese pharmacopoeia, fifth edition, 283, 1932).

For the experiment $100 \mathrm{cc}$. of egg-yolk solution prepared as above, were digested with $\frac{1}{2} \mathrm{~g}$. pancreatin. At the same time another $100 \mathrm{cc}$. of the solution were treated with viper venom, obtained from one viper (Agkistrodon blomhoffii) under the same condition.

The results show that a haemolytic substance of higher activity was formed more rapidly than with the pancreas extract. It is also noteworthy that the curves of pancreatin and viper venom show remarkable similarity.

(3) Isolation of lysolecithin from the digestion products of egg-yolk with pancreatin.

The method adopted in this experiment was

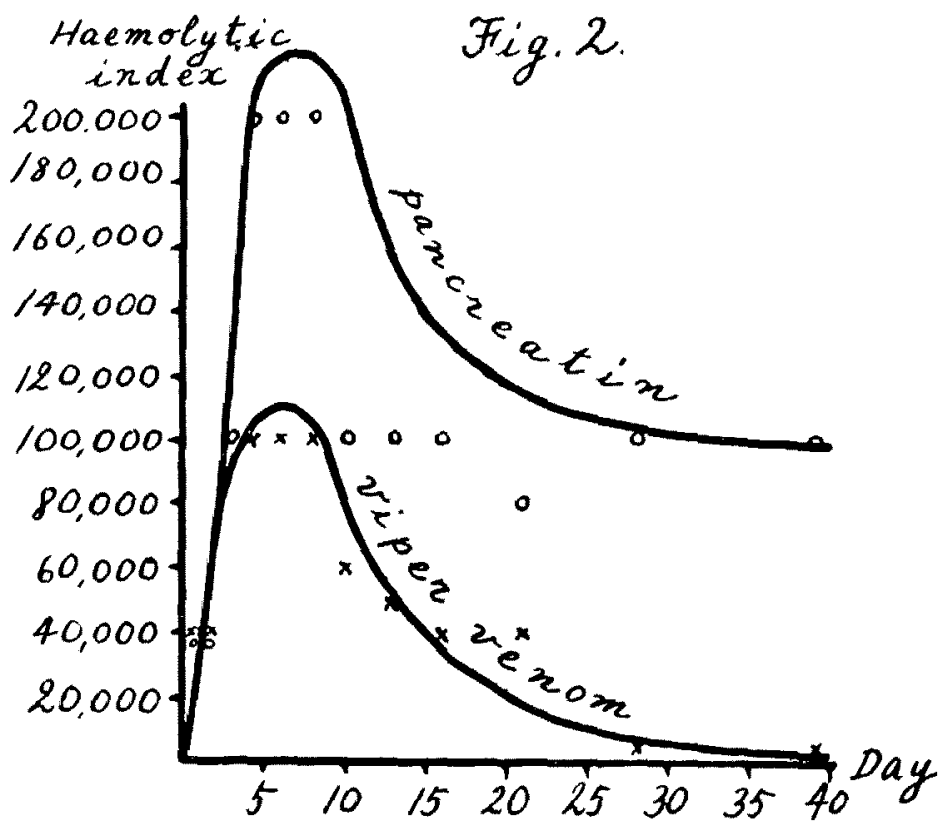
essentialy the same with that of Mr. Iwata (J. Agr. Chem. Soc. Japan, 6, 759, 1930; 7, 557, 1931 ; Bioch. Z. 224, 430, 1930).

30 fresh yolks $(515 \mathrm{~g}$.) were mixed with $500 \mathrm{cc}$. of $\mathrm{N} / 15$ potassiumphosphate solution and treated with $5 \mathrm{~g}$. pancreatin. The mixture was kept at $36-38^{\circ}$ for $2 \frac{1}{2}$ hours with frequent shaking, no antiseptic being used in this case. It was then poured into an equal volume of warm $95 \%$ alcohol, filtered, the residue was washed twice with each $400 \mathrm{cc}$. $85 \%$ alcohol. Both filtrate and washings were united and evaporated in vacuum until about 80 gramms thick brown syrup was obtained. This syrup was again dissolved in $200 \mathrm{cc}$. absolute alcohol and filtered, 
the insoluble residue was washed three times with each $20 \mathrm{cc}$. absolute alcohol. The combined filtrate thus obtained was now added with $15 \mathrm{~g}$. cadmium chloride, dissolved in $250 \mathrm{cc}$. hot absolute alcohol, whereby a white voluminous precipitate was formed. After addition of $300 \mathrm{cc}$. acetone the cadmium precipitate was filtered, washed five times with a mixture of alcohol and acetone, and dried in a vacuum desiccator. A white powder was thus obtained. The yield was $31 \mathrm{~g}$. and the haemolytic index about 60,000 . The cadmium double salts, obtained as above, was now suspended in a mixture of $100 \mathrm{cc}$. chloroform and $50 \mathrm{cc}$. of absolute alcohol, and decomposed by adding $80 \mathrm{cc}$. of $4 \%$ alcoholic ammonia. The precipitated cadmium hydroxide was centrifuged off and the clear filtrate was evaporated to dryness, treated with $50 \mathrm{cc}$. absolute alcohol, filtered from the insoluble residue and the clear brown filtrate was poured into $1 \frac{1}{2}$ litre ether, whereby the crude lysolecithin was precipitated. Yield $5 \frac{1}{2} \mathrm{~g}$.

This crude product which contained lysokephalin was recrystallized from absolute alcohol, alcohol and chloroform, pyridin, chloroform, alcohol and acetone and finally from alcohol and chloroform. In this way the lysolecithin was obtained as colourless nice prisms. Yield ca. $\frac{1}{2}$ g.

The lysolecithin, purified as above, is slightly hygroscopic. Heated in a sealed capillary, it begins to soften at $95^{\circ}$ and decomposes to a brown liquid at $262-263^{\circ}$. The haemolytic index is 320,000. Mixed with the lysolecithin prepared by Mr. Iwata, using cobra venom, no depression of decomposition point was observed. The analysis gave the following results.

$\begin{array}{lcccccc}\text { sample } & \text { method } & \mathrm{C} \% & \mathrm{H} \% & \mathrm{P} \% & \mathrm{~N} \% & \text { Amino N/Total N } \\ \text { (1) } 4.188 \mathrm{mg} . & \text { Liebig's } & 58.24 & 10.26 & & & \\ \text { (2) } 4.119, & \text { " } & 58.16 & 10.23 & & & \\ \text { (3) } 5.144, \text { Lieb's } & & & 5.95 & & \\ \text { (4) } 4.680, & \text { Dumas' } & & & & 3.00 & \\ \text { (5) } 5.941, & \text { " } & & & & 2.97 & \\ \text { (6) } 10.308, & \text { van Slyke's } & & & & & 3 / 100 \\ \text { mean } & & 58.20 & 10.24 & 5.95 & 2.98 & 3 / 100 \\ \text { theory }\left(\mathrm{C}_{24} \mathrm{H}_{50} \mathrm{PNO}_{7}\right) & 58.12 & 10.17 & 6.26 & 2.82 & 0 / 100\end{array}$

\section{Summary.}

When egg-yolk lecithin was digested with pancreas extract or commercial pancreatin, a powerful haemolytic substance was formed as the intermediate product. This substance was isolated in pure crystalline state, and was proved to be lysolecithin. It was identical in every respect with lysolecithin formed from lecithin by the action of snake venom. (June 20, 1932). 